\title{
NEGOTIATING AND REACHING AN ADMISSION OF GUILT AGREEMENT IN BOSNIA AND HERZEGOVINA
}

\author{
Miroslav Baljak \\ Evropski univerzitet KALLOS, Tuzla, Bosna i Hercegovina
}

CMESTE

JEL Kategorija rada: K14

\begin{abstract}
Apstrakt
Kao ratio legis uvođenja instituta sporazuma o priznanju krivice u naš krivičnoprocesni sistem navodi se želja za bržim okončanjem krivičnih postupaka kao i smanjenje troškova postupka, a da se time ne ugroze interesi zakonitosti i pravičnosti. Suština sporazuma o priznanju krivice (nagodbe) jeste prihvatanje krivičnopravne sankcije bez suđenja. Uvođenjem instituta sporazuma o priznanju krivice omogućava se pojednostavljenje krivičnog postupka u kojem dolazi do izražaja dispozicija stranaka krivičnopravnog odnosa, bez aktivnog učešća suda u fazama pregovaranja o krivici i zaključenja sporazuma, no ipak, uloga suda je odlučujuća u fazi razmatranja sporazuma: sud odbacuje ili prihvata podneseni sporazum. Na osnovu člana 231. stav. 1 ZKP BiH osumnjičeni, odnosno optuženi i njegov branilac mogu do završetka glavnog pretresa, odnosno pretresa pred apelacionim većem pregovarati s tužiocem o uslovima priznavanja krivice za delo za koje se osumnjičeni, odnosno optuženi tereti.
\end{abstract}

Ključne reči: sporazum, priznanje, krivica, pregovaranje, zaključivanje

\begin{abstract}
The ratio legis of introducing a plea bargain into our criminal justice system is the desire to end criminal proceedings more quickly and to reduce the costs of proceedings without compromising the interests of legality and fairness. The essence of a plea agreement (settlement) is accepting a criminal sanction without trial. The introduction of the plea agreement allows for simplification of the criminal procedure in which the disposition of the parties to the criminal relationship is expressed, without the active participation of the court in the stages of negotiation and conclusion of the agreement, however, the role of the court is decisive in the stage of considering the agreement: the court rejects or accepts the agreement filed. According to Article 231. para. 1 of the BiH Criminal Procedure Code, the suspects, that is, the accused and his defense counsel, may, until the end of the main trial or trial before the

Adresa autora: Miroslav Baljak

丢”baljak.miroslav@gmail.com

Appellate Panel, negotiate with the Prosecutor the terms of pleading guilty to the offense charged against the suspect or accused.
\end{abstract}


Keywords: agreement, recognition, guilt, negotiation, conclusion

\section{UVOD}

Pregovaranje o krivici je procesna ustanova koja je, kao efikasan model završetka krivičnog postupka, najzastupljenija u angloameričkom (adversarnom) sistemu krivičnog postupka, a karakteriše je potpuni izostanak dokaznog postupka. (Simović, N. M, 2006, 75) Strankama se omogućava sporazumevanje o krivici i sankciji i time stvara mogućnost okončanja postupka presudom na osnovu sporazuma stranaka pre i izvan glavne rasprave.

Pregovaranje o krivici se uopšteno shvata kao proces pregovaranja između osumnjičenog, odnosno optuženog i tužioca u kojem osumnjičeni , odnosno optuženi priznaje da je počinio krivično delo. (Baljak, M, \& Erkić, D, 2019, 285) Predmet pregovora su uslovi o priznanju krivice za delo za koje se osumnjičeni, odnosno optuženi tereti. Osumnjičeni, odnosno optuženi svojim aktivnim učešćem, davanjem iskaza omogućava saznavanje istine, a državni tužilac zauzvrat pristaje na davanje određenih ustupaka. (OSCE, 2006, 8). Ustupci, po ZKP BiH, koje tužilac može predložiti, su: izricanje kazne ispod zakonom određenog minimuma kazne zatvora za to krivično delo, odnosno blaža krivičnopravna sankciju za osumnjičenog, odnosno optuženog u skladu s krivičnim zakonom.

\section{SUBJEKTI PREGOVARANJA O KRIVICI}

$\mathrm{Na}$ osnovu člana 231. stav. $1 \mathrm{ZKP} B \mathrm{BiH}$ osumnjičeni, odnosno optuženi i njegov branilac mogu do završetka glavnog pretresa, odnosno pretresa pred apelacionim većem pregovarati s tužiocem o uslovima priznavanja krivice za delo za koje se osumnjičeni, odnosno optuženi tereti. Učešće Suda u fazi pregovaranja o uslovima priznanja krivice potpuno je isključeno. Procesna aktivnost Suda počinje tek kada se sporazum sačinjen u zakonskoj formi dostavi na razmatranje. (Sijerčič - Čolić, et.al, 2005, 622). Dakle, subjekti pregovaranja o krivici su:

1. osumnjičeni, odnosno optuženi i njegov branilac i

2. tužilac.

\subsection{Osumnjičeni, odnosno optuženi i branilac kao subjekti pregovaranja o krivici}

Zakon ne propisuje uslove pod kojima se odvija pregovaranje o krivici, tako da se može reći da je strankama, odnosno tužiocu, osumnjičenom, odnosno optuženom i njegovom braniocu ostavljena potpuna sloboda prilikom pregovaranja o uslovima priznanja krivice. (Bajić, $M$, et. al, 2006, 36) Ako osumnjičeni nema branioca (izjasni se za ličnu odbranu ili po zakonu ne postoje uslovi za obaveznu odbranu), pregovori o priznanju krivice između tužioca i osumnjičenog, posebno u fazi istrage na prvom ispitivanju pre podizanja optužnice, trebali bi da se vode sa izuzetnim oprezom - naročito se to odnosi na osumnjičenog. S toga je vrlo značajno, već na prvom ispitivanju, kako će osumnjičeni iskoristiti svoje pravo na odbranu, odnosno da li će se braniti sam ili uz stručnu pomoć branioca. Stručna pomoć branioca, tzv. formalna odbrana (Simović, N. M, 2005, 146) može biti po zakonu: obavezna odbrana, fakultativna odbrana i odbrana siromašnih. Dakle, pregovaranje o uslovima priznanja krivice osumnjičenog sa tužiocem može početi još u fazi istrage, što za osumnjičenog bez branioca može biti odlučujuće za dalji tok postupka. Naime, na prvom ispitivanju u istrazi, kojeg vrši ovlašteno službeno lice ili tužilac, osumnjičeni mora biti obavešten o delu za koje se tereti i osnovama sumnje protiv njega i da njegov iskaz može biti korišten kao dokaz u daljem toku postupka, a ukazaće mu se i na sledeća prava:

- da nije dužan izneti svoju odbranu niti odgovarati na postavljena pitanja,

- da može uzeti branioca po svom izboru koji može biti prisutan njegovom ispitivanju, kao $\mathrm{i}$ da ima pravo na branioca bez naknade $u$ slučajevima predviđenim zakonom,

- da se može izjasniti o delu koje mu se stavlja na teret $\mathrm{i}$ izneti sve činjenice i dokaze koji mu idu u korist i ako to učini u prisustvu branioca da je takav njegov iskaz dopušten kao dokaz na glavnom pretresu i da bez njegove saglasnosti može biti pročitan i korišten na glavnom pretresu,

- da ima pravo u toku istrage razmatrati spise i razgledati pribavljene predmete koji mu idu $u$ 
korist, osim ako je reč o spisima i predmetima čije bi otkrivanje moglo dovesti u opasnost cilj istrage,

- da ima pravo na besplatne usluge prevodioca ako ne razume ili ne govori jezik koji se koristi prilikom ispitivanja (čl. 78. st. 2. ZKP BiH).

Osumnjičeni se može dobrovoljno odreći navedenih prava, ali njegovo ispitivanje ne može započeti dok se njegova izjava o odricanju ne zabeležii pismeno i dok ne bude potpisana od strane osumnjičenog. Osumnjičeni se ni pod kojim okolnostima ne može odreći prava na prisustvo branioca ako je njegova odbrana obavezna po zakonu (čl. 78. st. 3. ZKP BiH).

Interesi osumnjičenog odnosno optuženog za iniciranje ili stupanje u pregovore sa tužiocem, su sledeći: izvesnost dobijanja blaže kazne odnosno sankcije, smanjenje troškova koje bi imao u slučaju donošenja osuđujućih presuda kada troškove snosi optuženi, takođe nema izdataka u vidu naknade braniocu ili su vrlo mali, a i često nema glavnog pretresa, te nije izložen svemu onome što je neizbežno u toku trajanja postupka.

Ako osumnjičeni, odnosno optuženi ima branioca (izabranog ili postavljenog), u pregovaranju o krivici učestvuje i branilac osumnjičenog, odnosno optuženog, te će se, u pravilu, pregovaranje odvijati između branioca i tužioca, s tim da je branioc o toku i sadržaju pregovora dužan obaveštavati osumnjičenog, odnosno optuženog. (Filipović, Lj. et. al, 2006, 71) Obaveze branioca prema njegovom klijentu $u$ toku pregovora o sporazumu o priznanju krivice nisu jasno definisane u zakonu. Najmanje što može da učini branilac je to da treba da prenese sve ponude tužioca i treba da obezbedi da njegov klijent promišljeno uđe u sporazum, kako se to ne bi rešavalo tokom procesa usvajanja sporazuma od strane suda. Dobar branilac će, takođe, zaštititi interese svog klijenta pomažući mu da oceni kvalitet onoga što mu tužilac nudi u nagodbi i savetujući ga kako da ne naškodi svom slučaju tokom procesa pregovora.

Branilac ne može savetovati svog klijenta da prihvati ili ne prihvati sporazum o priznanju krivice ako ne razume ozbiljnost klijentovog slučaja $i$ šanse za nepovoljnu presudu na suđenju. Pre sporazuma, branilac bi trebao da napravi preliminarnu istragu činjenica. Branilac bi morao da zna nešto više o klijentovoj prošlosti. Da li je njegov klijent ovisnik o drogama i alkoholu i da li je neka hemijska supstanca mogla uticati na njegovo ponašanje, što bi umanjilo njegovu krivičnu odgovornost. Da li je ranije bio osuđivan, što bi bila otežavajuća okolnost na suđenju ili je optužen po prvi put? Koliko god je moguće, branilac bi takođe trebao da utvrdi koji bi svedoci mogli biti važni za suđenje, da li su dostupni i pouzdani, da utvrdi što više detalja o mestu zločina, materijalnim dokazima, podacima koji su dostupni u preliminarnoj oceni dokaza, te mogućnosti za pomoć veštaka. Ovi faktori će ukazati na snagu odbrane u odnosu na tužilaštvo. Istraživanje koje odbrana sprovodi kao deo pripreme za suđenje, dodatno je korisno za proces sporazuma o priznanju krivice. Branilac bi morao znati tačke optužnice ili koje će tačke optužnica na kraju sadržavati, koje elemente tužilaštvo mora dokazati, koji su dozvoljeni dokazi, koja je moguća odbrana i koji je opseg moguće kazne. Zajedno sa istragom činjenica, ova istraga će ukazati kakve su šanse za proglašenje klijenta krivim. Osim toga, ukazaće kolike su šanse da optuženi dobije povoljniju kaznu, ako bude proglašen krivim te daje bolji uvid u okvire u kojima se branilac može kretati tokom pregovora o priznanju krivice. Mudar branilac će, pored ostalog, prostudirati i ličnost tužioca i sudije. Branilac će proučiti koliku slobodu odlučivanja tužilac ima u i pogledu pregovora o krivici, njegovu reputaciju, koliko ima predmeta, i njegove prethodne slučajeve na sudu, koliko je ambiciozan, uticaj koji oštećena strana ili porodica oštećene strane imaju na njega i njegovo zalaganje za slučaj. Takve informacije će pomoći braniocu da utvrdi u kojoj meri je tužilac spreman da postigne sporazum umesto da ide na suđenje, koliko je spreman da blefira tokom pregovora i u kakvoj nepovoljnoj situaciji bi tužilac bio ukoliko ne postigne nagodbu. Sa druge strane, ovo ukazuje na procenat verovatnoće da branilac dobije dobru ponudu tokom pregovora, koliko daleko odbrana može ići tokom pregovora i koliki je rizik u slučaju da dođe do suđenja. Što se tiče sudije, branilac bi trebao da se raspita o tome koliko je taj sudija spreman da prihvati sporazum o priznanju krivice, koliko je predusretljiv prema različitim uslovima kažnjavanja i kakve su obično njegove odluke kada se sličan predmet pojavi na sudu. Ovi podaci pomažu braniocima da provere kolike su šanse da sporazum o priznanju krivice bude 
usvojen na sudu i da li je sudija sklon tome da predmet ide na suđenje. Sve ovo pomaže advokatu da proceni situaciju i posavetuje svog klijenta da prihvati sporazum kad je on jedino realno rešenje, pa čak i kada predviđa kraću zatvorsku kaznu, jer bi u slučaju odlaska na suđenje njegov klijent dobio veću kaznu.

Po završetku neophodnih priprema, branilac bi trebao da pripremi svog klijenta i da ga upozori da ne nanese štetu svom slučaju tokom pregovora. Norme o pregovaranaju o krivici u $\mathrm{BiH}$ će se formirati kroz praksu, međutim, trenutno postoji veliki broj zamki u koje bi optuženi mogao upasti. Tužioci imaju priliku da prisile optuženog na sporazum koji mu uopšte ne ide u korist. $\mathrm{Na}$ primer, tužilac tada može pokušati da napravi sporazum tako što će dobrovoljno odustati od tačaka optužnice koje uopšte nisu trebale u njoj da se nalaze. Rezultat takvog sporazuma je kazna koja bi bila ista kao i kada bi klijent bio proglašen krivim u krivičnom postupku. Dovesti osumnjičenog odnosno optuženog u zabludu, navodeći ga da prizna krivicu, tako što će misliti da je njegov slučaj mnogo ozbiljniji nego što zaista jeste predstavlja ne-etično ponašanje tužioca vredno prekora. Branilac bi trebao da se odbrani tako što će ponovo proveriti sve tačke optužnice i naglasiti one, za koje smatra da ih tužilac neće moći dokazati na suđenju kao i one koje smatra irelevantnim za pregovore o priznanju krivice, po drugim tačkama optužnice.

Branilac bi trebao da zaštiti klijenta i od situacija gde tužilac ulazi u proces pregovaranja sa namerom da izmami određene informacije od osumnjičenog, odnosno optuženog a bez stvarne namere da nastavi proces pregovora. Branioci treba da izbegavaju otkrivanje detalja svog slučaja sve dok se ne postigne sporazum. $\mathrm{Na}$ primer, u slučajevima gde klijent odluči da svedoči protiv neke druge osobe, u zamenu za povoljniju kaznu, tužilac neće sklopiti sporazum sve dok ne sazna tačan sadržaj svedočenja. Branilac i njegov klijent tada mogu pregovarati sa tužiocem na osnovu tzv. preliminarne procene dokaza. Tokom preliminarne procene dokaza, klijent će tužilaštvu reći ono što mu je poznato. Ako je tužilac zadovoljan njegovim iskazom i ako smatra da je istinit, pouzdan i koristan, verovatno će biti voljan da pregovara o preciznijim komponentama sporazuma. Ako tužilac smatra da informacija nije tačna ili nije od velike koristi, može odlučiti da ne sklopi sporazum. Ipak, u slučajevima gde je klijent dao dosta informacija koje ukazuju na njegovu krivicu, tužilac će se naći $u$ iskušenju da tokom svoje istrage sledi smernice dobijene tokom preliminarne procene dokaza, što će mu pomoći da dođe do osuđujućih dokaza izvan preliminarne procene. ZKP BiH ne predviđa zaštitu od ovakvih situacija, prema tome, branilac je dužan da se pobrine da takve situacije spreči. Branilac bi trebao da unajmi stenografa koji bi zabeležio detalje preliminarne procene dokaza. Sve stranke koje učestvuju u ovom procesu bi trebale da potpišu zapisnik sa preliminarne procene. Branilac bi, takođe, trebao od tužioca da sazna, putem dobrovoljnje razmene informacija ili obavezne razmene dosijea, koji se dokazi nalaze u dosijeu do dana održavanja preliminarne procene dokaza.

\subsection{Tužilac kao subjekt pregovaranja o krivici.}

Interesi i motivi tužioca za stupanje u pregovore su sledeći: donosi se osuđujuća presuda na koju se žalba ne može ulagati zbog izrečene krivičnopravne sankcije; efikasnost i brzina rešavanja krivične stvari, najčešće, bez provođenja glavne rasprave; smanjenje troškova postupka, odnosno ušteda resursa koje je neophodno angažovati na jednom slučaju; eventualni dolazak do kvalitetnih dokaza protiv drugih učinioca krivičnih dela, do kojih ne bi mogao doći na drugi način, a koji mogu dovesti do njihovog optuženja i kažnjavanja, što je naročito važno kod raznih oblika organizovanog kriminala. (Bajić, M, et. al, 2006, 36)

Ako tužilac smatra da počinilac krivičnog dela predstavlja manju pretnju od nekog drugog počinioca, kao na primer u slučaju dilera marihuanom koji je povezan sa međunarodnim krijumčarima droge, tužilac može umanjiti kaznu za malog dilera u zamenu za informacije ili svedočenje koje će mu pomoći da locira i optuži počinioca teških krivičnih dela. Vrlo često tužilac će uslovljavati sklapanje sporazuma istinitim svedočenjem. Ukoliko tužilac utvrdi da je optuženi lagao pod zakletvom, sporazum o priznanju krivice se poništava a tužilac se može odlučiti da pokrene krivični postupak protiv optuženog. $U$ drugim situacijama, tužilac može pregovarati o sporazumu bez prisustva oštećene strane. Tužilac će, na primer, želeti da izbegne da žrtvu 
silovanja izlaže suđenju. Putem sporazuma, tužilac ipak može primorati optuženog da odsluži kaznu zatvora, verovatno manju od one koja bi mu bila izrečena ako bi došlo do suđenja. $\mathrm{Na}$ kraju, sporazum dozvoljava tužiocu da osigura osudu u slučajevima kada oseća da je osumnjičeni, odnosno optuženi kriv, a zna da će imati problema da obezbedi dokaze za suđenje na primer, ključni svedok je nestao. Da li će tužilac odlučiti da razmatra sporazum o priznanju krivice, zavisiće od niza subjektivnih elemenata, kao npr. obim predmeta, vreme provedeno $u$ istrazi, prethodna krivična dela osumnjičenog, uticaj žrtvine porodice, te nivo medijske pažnje. Zakon takođe propisuje nekoliko formalnih obaveza za tužioca tokom procesa pregovaranja. Nedostatak zakonom propisanih odgovornosti daje tužiocu dovoljno prostora za naizgled strateško, ali veoma ne-etično ponašanje. $\mathrm{Na}$ primer, zakon ne sadrži odredbu koja bi tužiocu branila da koristi proces pregovaranja o krivici da bi ohrabrio osumnjičenog, odnosno optuženog da otkrije inkriminišuće podatke koji bi optuženom bili od koristi $u$ istrazi a da potom ne održi obećanje. Tužilac, takođe, može podići okvirnu optužnicu, što bi mu ostavilo dovoljno prostora za proces pregovora. Postoje mere koje branioci mogu preduzeti u cilju sprečavanja takve prakse, međutim, obazriv tužilac će nastojati da radi u okviru svojih ovlaštenja. Ako tužilac stekne lošu reputaciju biće mu znatno teže da nađe branioce sa kojima bi eventualno ugovorio sporazum o priznanju krivice. $U$ principu, tužilac bi trebao da pokuša da utvrdi odgovornost optuženog za suštinu počinjenog dela. Tužilac ne bi trebao da ponudi blažu kaznu samo zato da bi smanjio broj predmeta, niti bi trebao namamiti nevino optužene da priznaju krivicu. Ako odbrana prezentuje dokaze koji ukazuju da je branjenik pogrešno optužen, da je optužen za zločin, mnogo ozbiljniji od onog koji je počinio ili da ga optužuje pojedinac za koga tužilac zna da ima reputaciju nepoštene osobe, tužilac mora preduzeti potrebne korake da spreči nastanak nepravde.

Generalno, tužilac ne bi trebalo da inicira i vodi pregovore sa osumnjičenim, odnosno optuženim koji nema branioca, ukoliko isti nije upoznat sa svim činjenicama i dokazima kojima tužilaštvo raspolaže ili nije bio upoznat sa svojim pravom da mu budu predočene sve te činjenice i dokazi. Od suštinske je važnosti za tužioca da takve pregovore treba voditi samo onda kada je sasvim jasno da im osumnjičeni, odnosno optuženi pristupa dobrovoljno, svesno i sa razumevanjem svih mogućih posledica. Tužilac bi prvo trebalo da posavetuje osumnjičenog odnosno optuženog da ima pravo uzeti branioca po svom izboru, kao i da ima pravo na branioca bez naknade $u$ slučajevima predviđenim zakonom. Ako osumnjičeni odnosno optuženi odbije da angažuje branioca tužilac bi trebalo da obezbedi prisustvo trećeg lica pregovorima radi održavanja kontakta na distanci. Može da se vodi zapisnik tokom citavih pregovora, iako zakon to striktno ne predviđa. Pri pregovaranju o krivici, a obzirom da zaključeni sporazum ide na ocenu suda, tužilac bi morao voditi računa o tome, da li je osumnjičeni odnosno optuženi: uračunljiv, sposoban da shvati značaj svog dela i da upravlja svojim postupcima; da li razume prirodu i sadržinu pregovora; da li je svestan kojih se prava odriče, koje obaveze prihvata, koje prednosti ima od eventualnog zaključenja sporazuma, ali $i$ toga da se odriče prava na suđenje i prava žalbe na krivičnopravnu sankciju. Osim obavezujućih načela legaliteta i oficijelnosti, tužilaštvo u pregovorima o priznanju krivice, treba voditi računa i o: 1) pravednosti i istinitosti i 2) otvorenosti i preciznosti.

Pravednost $i$ istinitost. Tužilac treba učestvovati u pregovorima o rešavanju krivične stvari: kada predmet ispunjava uslove za vođenje krivičnog postupka (npr. kada tužilac donese naredbu o sprovođenju istrage iz čl. 216. ZKP BiH) i kada je pristanak osumnjičenog odnosno optuženog da prizna krivicu kako dobrovoljan tako i dat uz potpunu informisanost o tom činu. Prilikom pregovaranja o krivici i zaključivanja sporazuma tužilac ne sme prisiljavati na bilo koji način, primoravati niti ucenjivati osumnjičenog, odnosno optuženog da prizna krivično delo i zaključi sporazum. Prilikom pregovaranja i zaključivanja sporazuma tužilac treba da isključi svaku delatnost koja bi mogla da utiče na učinioca krivičnog dela, tj. koja bi mogla da utiče na njegovu slobodnu volju prilikom izjašnjavanja o krivici i elementima eventualnog sporazuma. Tužilac treba da nastoji da optuženi u potpunosti prizna krivično delo za koje se tereti, odnosno priznaje jedno ili više od krivičnih dela učinjenih u sticaju koja su predmet optužbe. To znači da optuženi treba istinito dati kompletan činjenični 
opis događaja iz kojeg bi se detaljno utvrdili elementi bića krivičnog dela ali i kvalifikacija dela kao i krivica optuženog. (Ilić, G. et. al, 2009, 217) Tužilac treba da nastoji da optuženi u svom priznanju detaljno opiše izvršenje krivičnog dela, samu radnju izvršenja dela, pobude i motive, pripremanje dela, ponašanje, otkrivanje sredstava za izvršenje dela, da objasni način nabavljanja tih sredstava, sam čin izvršenja dela, ponašanje nakon izvršenog dela. Tužilac treba da nastoji da ubedi optuženog da preda sredstva kojima je delo izvršeno i druge materijalne dokaze koji potvrđuju da je baš optuženi izvršio delo. Tužilac pri uzimanju priznanja od optuženog treba da uloži sve napore kako bi otkrio detalje pri izvršenju dela koji mogu biti poznati samo izvršiocu a koji će biti detaljno argumentovani i koji njegovo priznanje ne bi dovodili u sumnju. Priznanje optuženog ne znači da tužilac ne treba da isto proveri i nekim drugim dokazima.

Svi sporazumi o priznanju krivice treba da budu ispunjeni od strane tužilaštva, osim kada bi njihovo izvršenje bilo očigledno suprotno javnom interesu. Na primer, tužilac ne treba nastaviti sa zaključivanjem sporazuma o priznanju krivice ako ima razloga da veruje da nisu ispunjeni kriterijumi postavljeni u čl. 216. ZKP BiH. Dodatno, tužilac može opravdano odbiti da realizuje sporazum ukoliko su mu pogrešno bile predstavljene činjenice slučaja. Kada osumnjičeni odnosno optuženi promeni branioca tužilac treba da upozna novog zastupnika odbrane o ponudama koje je dao prethodnom i o stavu tužilaštva u konkretnom predmetu.

Kako je postizanje sporazuma o priznanju krivice u ranoj fazi postupka blagotvorno za ostvarenje pravde, tužilaštvo treba da učini ponudu osumnjičenom odnosno optuženom čim se za to steknu okolnosti. Pre nego što predloži kaznu, tužilac treba da preduzme sve razumne mere potrebne da proceni koja je to odgovarajuća kazna (npr. kod novčane kazne, potrebno je izvršiti odgovarajuće procene o tome da li je optuženi u mogućnosti da je plati).

Otvorenost i preciznost. Tužilac bi, kada je god to moguće, trebalo da zatraži i uzme u obzir mišljenja učesnika u postupku - posebno oštećenog (ako ga ima). U toku pregovaranja $\mathrm{i}$ zaključenja sporazuma o priznanju krivice tužilac bi trebao da vodi računa i štiti interese i prava oštećenog, a posebno da pruži mogućnost oštećenom da se izjasni o imovinsko pravnom zahtevu. Ipak, posle tih konsultacija sa oštećenim, konačnu odgovornost za procenu podobnosti slučaja za sklapanje sporazuma o priznanju krivice snosi tužilaštvo. Pod određenim okolnostima, može se dogoditi da se opseg tih konsultacija ograniči iz razloga očuvanja privatnosti ili čuvanja tajne $u$ interesu optuženog ili opštem interesu čitave zajednice. Kada dođe do zaključenja sporazuma o priznanju krivice, tužilac treba da podnese taj sporazum sudu. Pod određenim okolnostima, neki aspekti postignutog sporazuma će biti raspravljani sa sudijom nasamo. Do toga može doći samo u retkim i izuzetnim situacijama kada javno iznošenje činjenica nije u interesu šire javnosti ili optuženog (npr. teška faza bolesti optuženog, ili činjenica da je on bio prikriveni saradnik policije, tužilaštva). Tužilaštvo treba u spisima predmeta da čuva precizne zapisnike o svim pregovorima 0 priznanju krivice kao i tekstove samih sporazuma. Time će se obezbediti konzistentna i dobro proučena praksa.

Određena postupanja tužioca ne smeju biti prihvatljiva u fazi pregovora (nagodbe) sa odbranom, a to se pre svega odnosi na davanje saglasnosti u vezi sa činjenicama koje mogu zaista ili samo prividno dovesti sud u zabludu, kao što su:

- saglasnost - nagodba da se sud ne upozna sa nekim podacima iz krivične evidencije optuženog ako je to od značaja za konkretan predmet ili može biti od pomoći sudu u njegovom rešavanju;

- saglasnost - nagodba da se sud ne upozna sa težinom povrede ili obimom štete koju je oštećeni pretrpeo;

- saglasnost - nagodba da se od suda sakriju činjenice koje se mogu dokazati, relevantne su za konkretan predmet i mogu imati svojstvo otežavajućih okolnosti.

\section{VREME PREGOVARANJA O KRIVICI}

Osumnjičeni, odnosno optuženi i njegov branilac mogu pregovarati $s$ tužiocem o uslovima priznavanja krivice za delo za koje se osumnjičeni, odnosno optuženi tereti - do završetka glavnog pretresa, odnosno pretresa pred apelacionim većem (čl. 231. st. 1. ZKP BiH). 
Problem vezan za pregovore $u$ fazi istrage je nedovoljnost dokaza za postojanja osnovane sumnje samim tim što optužnica još nije podignuta, te je stoga ishitreno inicirati pregovore $s$ bilo koje strane. U pravilu, osumnjičeni retko inicira pregovore $u$ fazi istrage, već to obično dolazi nakon potvrđivanja optužnice. Naime, u fazi istrage pre podizanja optužnice, pregovori između odbrane i tužioca o činjeničnom opisu krivičnog dela, pravnoj kvalifikaciji i o odustanku tužioca od teže kvalifikacije u zamenu za potpuno priznanje i drugim uslovima zaključenja sporazuma, mogu se odvijati samo nezvanično $i$ izuzetno. Dakle, izuzetno, kada postoje „jaki dokazi“" protiv osumnjičenog koji se tada najčešće nalazi u pritvoru, isti može inicirati pregovore, kada dobrovoljno pristaje na saradnju u vezi daljnjeg rasvetljavanja kriminalnih delatnosti pripadnika organizovanog kriminala. $U$ tom slučaju, kao bivši pripadnik, osumnjičeni može ponuditi ključne informacije ili pristati na svedočenje, a zauzvrat tražiti od tužioca ili imunitet od krivičnog progona ili odustanak od pojedinih tačaka optužbe ili smanjenje kazne ispod zakonom određenog minimuma kazne zatvora. ZKP BiH predviđa za predmet pregovora samo vrstu i visinu kazne, ali se pregovori u ovakvim slučajevima, mada nezvanično, mogu voditi i o sledećem: o vrsti i težini krivičnog dela te o pravnoj kvalifikaciji dela, naročito do potvrđivanja optužnice.

Nagodba u ranim fazama "boluje“ od teške neizvesnosti i asimetrije informacija koje stvaraju vrlo ozbiljne probleme kod pregovaranja. Ravnoteža je prilično komplikovana. Kako vreme prolazi, više informacija će biti dostupno (otuda manja verovatnoća grešaka), ali rastu i troškovi postupka. Dakle, tu je bitno optimalno vreme za sklapanje nagodbe. Problem je u tome što tužilac i osumnjičeni ne mogu imati istu percepciju vremena. Moguće je da troškovi imaju različite profile. Takođe, dostupnost novih informacija može zavisiti od dokaznih pravila i novih saznanja. Tužilac, takođe, može „racionalizovati“ odnosno uskratiti davanje informacija koje idu u prilog odbrani u fazi pregovora, tako da odbrana stiče dojam da je izvesna verovatnoća osude na eventualnom suđenju, te se može usled asimetrije informacija ishitreno odlučiti na sporazumno priznanje krivice. Naime, kako se vremenom jaz informacija produbljuje tako raste $\mathrm{i}$ uverenje da je bolje ići na sporazumno priznanje nego na suđenje. Drugim rečima, odbrana može biti „ubeđena" snagom dokaza od strane tužioca u veliku verovatnoću osude na suđenju iako nema sopstvenih dokaza - uverenja o tome.

\section{PREDMET I TOK PREGOVARANJA O KRIVICI}

Predmet pregovaranja o krivici su uslovi priznavanja krivice za delo za koje se osumnjičeni, odnosno optuženi tereti. Ti uslovi tiču se ustvari vrste i visine krivičnopravne sankcije odnosno sankcija koje bi se osumnjičenom odnosno optuženom izrekle za delo za koje se on tereti. (Filipović, Lj. et. al, 2006, 71) Drugim rečima, nagodba nije moguća o odustanku tužioca od krivičnog gonjenja, odnosno povlačenju optužnice, kao ni vezano uz činjenični opis dela koje se optuženom stavlja na teret.

Predmet pregovaranja o krivicu između tužioca i osumnjičenog, odnosno optuženom, može biti:

- izricanje kazne ispod zakonom određenog minimuma kazne zatvora za to krivično delo, odnosno

- blaža sankcija u skladu sa krivičnim zakonom (čl. 231. st. 3. ZKP BiH).

Dakle, tužilac može zatražiti izricanje jedne ili više sledećih krivičnopravnih sankcija: kaznu zatvora, novčanu kaznu, uslovnu osudu, meru sigurnosti (zabrana obavljanja određenih poziva, delatnosti ili dužnosti, i oduzimanje predmeta) i meru oduzimanja imovinske koristi.

Tužilac može ponuditi izricanje kazne ispod zakonskog minimuma primenom odredbi 0 ublažavanju kazne, blaža vrsta kazne, npr. izricanje novčane kazne umesto kazne zatvora ili pak blaža vrsta krivičnopravne sankcije, npr. uslovna osuda umesto kazne zatvora ili novčane kazne. Zakon ne ograničava stranke i branioca da krivičnopravnu sankciju precizno odrede, npr. šest meseci zatvora ili novčana kazna u iznosu od $5.000,00$ KM. (Sijerčič - Čolić, et.al, 2005, 622)

Tužilac se mora kretati u okvirima obaveznih propisa krivičnih zakona o vrstama i svrsi krivičnih sankcija, uslovima za njihovo izricanje, kaznama koje se mogu izreći za pojedina krivična dela i o granicama ublažavanja zakonom propisane kazne. 
Načelno, ne može biti predmet pregovaranja o krivici između tužioca i osumnjičenog odnosno optuženog:

- ako je, obavezno oduzimanje predmeta koji su upotrebljeni ili su bili namenjeni za učinjenje krivičnog dela ili koji su nastali učinjenjem krivičnog dela, ako postoji opasnost da će biti ponovo upotrebljeni za učinjenje krivičnog dela ili kada se u cilju zaštite opšte sigurnosti ili iz moralnih razloga oduzimanje čini neophodno, ako su vlasništvo učinioca. Ovi predmeti se mogu oduzeti i kada nisu vlasništvo učinioca ako to zahtevaju interesi opšte sigurnosti i interesi morala, ali time se ne dira u prava trećih lica na naknadu štete od učinioca (čl. 74. KZ BiH);

- ako je, obavezno oduzimanje imovinske koristi pribavljene krivičnim delom (čl. 110. KZ $\mathrm{BiH})$;

- ako je, obavezno krivično gonjenje (po načelu legaliteta, tužilac mora preduzeti krivično gonjenje čim se steknu uslovi predviđeni zakonom) - tužilac ne može pregovarati o nepreduzimanju krivičnog gonjenja za neka od krivičnih dela za koje se osumnjičeni, odnosno optuženi tereti;

- ako je, predložena neodgovarajuća kazna (kazna ispod najmanje mere kazne koja se može izreći za to krivično delo primenom odredbi krivičnog zakona o ublažavanju kazne); i

- ako je, predložena neodgovarajuća sankcija (uslovna osuda ili novčana kazna za delo za koje se ona, po krivičnom zakonu, ne može izreći).

Dakle, prilikom pregovaranja o krivici, tužilac mora voditi računa o zakonskim mogućnostima, tj. moraju se poštovati materijalno-pravne odredbe krivičnog zakona, pa tužilac može ponuditi samo ono što je predviđeno zakonom. Ukoliko to tužilac previdi, takav sporazum o priznanju krivice prilikom razmatranja sud ne sme prihvatiti.

Prilikom vođenja pregovora, sledeća postupanja tužioca nisu prihvatljiva:

- započeti ili nastaviti krivično gonjenje za dodatna krivična dela samo da bi se osiguralo opstajanje postignutog sporazuma 0 priznanju krivice;
- saglasiti se sa sporazumom o priznanju krivice u vezi krivičnog dela za koje nisu predloženi dokazi (tzv. tanak slučaj); ili

- saglasiti se sa priznanjem krivice i sa kaznom koja neadekvatno odražava težinu inkriminisanog ponašanja optuženog koje se može dokazati, osim u izuzetnim situacijama u kojima je priznanje krivice opravdano sa stanovišta ostvarenja pravde, zaštite društva ili zaštite optuženog.

Uslovi o kojima se pregovara između tužioca i osumnjičenog, odnosno optuženog mogu biti i oni elementi zbog kojih se sporazum zaista postiže a koji u sporazumu ne moraju biti navedeni, kao što su razni modaliteti saradnje osumnjičenog, odnosno optuženog sa tužiocem (npr. u slučaju kada je neophodno da se sačuva identitet budućeg svedoka saradnika i sl, ne mora se u sporazumu navesti koje je sve obaveze prihvatio saoptuženi). Činjenični opis i pravna kvalifikacija mogu biti uslovi o kojima se pregovara, ali neće biti poseban predmet sporazuma o priznanju krivice. Dogovoreni činjenični opis i pravna kvalifikacija, u slučaju saradnje osumnjičenog odnosno optuženog sa tužiocem, biće obavezni elementi optužnice koju će tužilac tek podneti ili izmenjene optužnice, a optuženi će zauzvrat u sporazumu o priznanju krivice u potpunosti priznati krivično delo iz tako podignute ili izmenjene optužnice.

Inicijativa za pregovore o krivici može poteći od bilo koje stranke ili od branioca, od momenta donošenja naredbe $\mathrm{o}$ sprovođenju istrage (Simović, N. M, 2006, 32) pa sve do završetka glavnog pretresa, odnosno pretresa pred apelacionim većem, u bilo kojoj fazi postupka. Kada inicijativu daje tužilac, u praksi će to biti najčešće preko branioca zato što je ta komunikacija lakše ostvarljiva, ali nije isključeno da ponudu učini neposredno osumnjičenom tako što će ga pozvati na ispitivanje.

Za sam predlog kojim se nude pregovori o priznanju krivice zakon ne traži pismenu niti bilo kakvu formu, te se dâ zaključiti da je to neformalni, faktički akt jedne od stranaka ili branioca. Otuda, stranke i branilac mogu predlog za početak pregovora da daju usmeno ili pismeno, telefonom, elektronskom poštom ili bilo kojim sredstvom komuniciranja. Izbor sredstva komuniciranja i forme u kojoj će se pregovori 
predložiti treba da odgovara procenjenom i potrebnom nivou konspirativnosti, koji zavisi od uslova o kojima će se pregovarati (npr. ako se nudi ili traži saradnja osumnjičenog, odnosno optuženog u otkrivanju ili dokazivanju drugih krivičnih dela i njihovih učinilaca, neophodan je neposredni usmeni razgovor i sl.).

Pregovori o uslovima priznanja krivičnog dela ili krivičnih dela koja se osumnjičenom, odnosno optuženom stavljaju na teret mogu započeti tek pošto suprotna strana prihvati učinjeni predlog. Mada zakon ne predviđa posebne uslove za vođenje postupka pregovaranja između stranaka o zaključenju sporazuma o priznanju krivice, koji se odvija najčešće u prostorijama javnog tužilaštva, sam tok pregovaranja o krivici se obično odvija na sledeći način:

- Pre početka pregovaranja tužilac je dužan da drugu stranu pouči: o pravu da može angažovati branioca i da je to poželjno zbog značaja pregovaranja i eventualnog zaključenja sporazuma o priznanju krivice; o zakonskim elementima sporazuma o priznanju krivice i njegovim prednostima; o pravima iz redovnog krivičnog postupka koja gubi u slučaju zaključenja sporazuma o priznanju krivice; o pravu da može odustati od predloga (datog ili ponuđenog) sve do zaključenja sporazuma o priznanju krivice.

- O toku pregovaranja vodi se zapisnik u koji se unosi: vreme početka, prekidanja, odlaganja i završetka pregovaranja; imena lica koja su prisutna pregovaranju; detaljne izjave učesnika pregovaranja o svim uslovima za zaključenje sporazuma (npr., za opuženog u odnosu na obavezne i fakultativne uslove, za oštećenog u odnosu na imovinskopravni zahtev, povrat ili oduzimanje predmeta i sl.).

- Pregovaranje otpočinje izlaganjem uslova za zaključenje sporazuma od strane predlagača, a potom se druga strana izjašnjava o datom predlogu, uz mogućnost odlaganja i predlaganja novih uslova.

- Ukoliko se postigne saglasnost o bitnim elementima sporazuma o priznanju krivice, sačinjava se poseban zapisnik o priznanju krivice optuženog, koji predstavlja sastavni deo sporazuma.

- Tužilac treba pozvati i oštećenog koji će dati izjavu o imovinskopravnom zahtevu na zapisnik o pregovaranju.
Odlaganje u fazi pregovaranja, po pravilu, može trajati do 15 dana.

- Zapisnik o pregovaranju potpisuju sva prisutna lica, sa konstatacijom da stranke nemaju primedbe.

- Nakon postignute saglasnosti stranaka o svim elementima i pribavljenih dokaza, pristupa se zaključenju sporazuma o priznanju krivice.

\section{ZAKLJUČENJE SPORAZUMA O PRIZNANJU KRIVICE}

Sporazum o priznanju krivice se zaključuje uz saglasnost slobodnih volja državnog tužioca, s jedne strane i optuženog (i njegovog branioca), s druge strane. Ovaj sporazum mora biti sačinjen u pisanoj formi, te potpisan od tužioca i optuženog (i njegovog branioca). Optuženi dobrovoljno, svesno i s razumevanjem u potpunosti priznaje krivicu za jedno ili više krivičnih dela, koja su predmet optužbe. U sporazumu, tužlac može predložiti izricanje kazne ispod zakonom određenog minimuma kazne zatvora za to krivično delo, odnosno blažu sankciju za optuženog u skladu s krivičnim zakonom. Zakon ne ograničava stranke u pogledu zaključenja sporazuma s obzirom na visinu zaprećene kazne zatvora.

Sporazum o priznanju krivice ne može se zaključiti ako se optuženi na ročištu za izjašnjavanje o krivici izjasnio da je kriv. (čl. 231. st. 2. ZKP BiH). Pregovori o uslovima priznanja krivice između odbrane i tužioca se mogu početi odvijati još u fazi istrage, ali do zaključenja sporazuma o priznanju krivice između optuženog i branioca, s jedne strane, i tužioca, s druge strane, može doći samo ako sudija za prethodno saslušanje, nakon potvrđivanja optužnice, na održanom ročištu za izjašnjenje o krivici zapisnički konstatuje da optuženi poriče krivicu izričito ili prećutno (ukoliko se optuženi ne izjasni o krivici, bilo da uopšte ne želi da se izjasni ili nije siguran kako da se izjasni u datom momentu, tada će sudija za prethodno saslušanje po službenoj dužnosti uneti u zapisnik da optuženi poriče krivicu). Dakle, sporazum o priznanju krivice se može zaključiti i dostaviti Sudu, uz prethodno potvrđenu optužnicu, ako na ročištu za izjašnjenje $\circ$ krivici sudija za prethodno saslušanje unese u zapisnik izjavu o poricanju krivice optuženog. 


\section{ZAKLJUČAK}

Načelo ekonomičnosti i efikasnosti poslednih 20. godina uzima sve više maha u evropskim državama (Italija, Njemačka, Francuska, Hrvatska ...) u kojima se tradicionalni krivični postupak u sve većoj meri zamenjuje pregovorima o priznanju krivice između odbrane i državnog tužioca. Ipak, u nekim evropskim državama postoje jasna ograničenja u pogledu predmeta nagodbe s obzirom na vrstu dela kao $\mathrm{i}$ obavezno prisustvo suda $u$ verifikovanju nagodbe, dok u SAD državni tužilac disponira ne samo visinom kazne već i predmetom optužbe bez obzira na težinu dela.

Osnovni razlog uvođenja instituta sporazum o priznanju krivice u krivičnoprocesni sistem $\mathrm{BiH}$ je pragmatične prirode (korisnost) - brže okončanje i smanjenje troškova krivičnih postupka, a da se time ne ugroze interesi zakonitosti i pravičnosti. Uvođenjem instituta sporazuma o priznanju krivice omogućava se pojednostavljenje krivičnog postupka u kojem dolazi do izražaja dispozicija stranaka krivičnopravnog odnosa, bez aktivnog učešća suda u fazama pregovaranja o krivici i zaključenja sporazuma, no ipak, uloga suda je odlučujuća u fazi razmatranja sporazuma: sud odbacuje ili prihvata podneseni sporazum. (Baljak, M, \& Erkić, D, 2015, 227)

Sporazum o priznanju krivice nije građanskopravni ugovor mada sadrži priznanje i činjenica i pravnih zaključaka, po čemu je blizak aktu priznanja tužbenog zahteva u građanskoj parnici. Budući da je to sporazum sui generis, a ne klasičan građanskopravni ugovor, on ne proizvodi neposredno dejstvo, već služi kao pravni osnov za donošenje presude o krivičnoj stvari. Institut sporazuma o priznanju krivice po svojoj pravnoj prirodi predstavlja „konsenzualnu pravdu“.

Prilikom razmatranja sporazuma o priznanju krivice zakon obavezuje sud da osigura da je optuženi svestan svojih prava i da se dobrovoljno odriče istih. Sud mora utvrditi da je do sporazuma o priznanju krivice došlo dobrovoljno, svesno i sa razumevanjem. Sud mora da proveri da li je optuženi svestan mogućih štetnih finansijskih posledica svog priznanja.

\section{CITIRANA DELA}

Bajić, M. et. al. (2006). Modul 4 - krivična oblast. Skraćeni krivični postupci. Javna ustanova CEST FBiH i CEST RS. Sarajevo: Visoki sudski i tužilački Savet BiH.

Baljak, M. (2015). Sporazum o priznanju krivice - Krivičnopravne sankcije. Zbornik radova. Tara: Udruženje za međunarodno krivično pravo.

Baljak, M. \& Erkić, D. (2019). Usklađenost pregovaranja o krivici u BiH sa Evropskom konvencijom za zaštitu ljudskih prava i osnovnih sloboda. Zbornik radova. Tara: Udruženje za međunarodno krivično pravo.

Filipović, Lj. et. al. (2006). Modul 2 - krivična oblast, Postupak optuženja i glavna rasprava. Javna ustanova CEST FBiH i CEST RS. Sarajevo: Visoki sudski i tužilački Savet BiH.

Ilić, G. et. al. (2009). Javnotužilački priručnik, drugo izmenjeno i dopunjeno izdanje. Beograd: Udruženje javnih tužilaca i zamenika javnih tužilaca Srbije.

OSCE Misija u Bosni i Hercegovini. (2006). Sporazum o priznanju krivice: primena pred sudovima BiH i usklađenost sa međunarodnim standardima za zaštitu ljudskih prava, drugo izdanje, Sarajevo.

Sijerčić-Čolić, H. et. al. (2005). Komentari zakona o krivičnom/kaznenom postupku u Bosni i Hercegovini, Savjet/Vijeće Evrope i Evropska komisija, Sarajevo: DES.

Simović, N. M. (2005). Krivično procesno pravo - uvod i opšti dio, Bihać: Pravni fakultet Univerziteta u Bihaću.

Simović, N. M. (2006). Krivično procesno pravo II (krivično procesno pravo - posebni dio), Banja Luka: PPGP Comesgrafika d.o.o. Banja Luka.

Zakon o krivičnom postupku BiH. (2003). 
Datum prve prijave:

Datum poslednje korekcije rada:

Datum prihvatanja članka:
20.02.2020.

27.03.2020.

07.04.2020.

Kako citirati ovaj rad? / How to cite this article?

Style - APA Sixth Edition:

Baljak, M. (2020, 04 15). Pregovaranje i zaključivanje sporazuma o priznanju krivice u Bosni i Hercegovini. (Z. Čekerevac, Ur.) FBIM Transactions, 8(1), 10-20. doi:10.12709/fbim.08.08.01.02

Style - Chicago Sixteenth Edition:

Baljak, Miroslav. 2020. „Pregovaranje i zaključivanje sporazuma o priznanju krivice u Bosni i Hercegovini.“ Urednik Zoran Čekerevac. FBIM Transactions (MESTE) 8 (1): 10-20. doi:10.12709/fbim.08.08.01.02.

Style - GOST Name Sort:

Baljak Miroslav Pregovaranje i zaključivanje sporazuma o priznanju krivice u Bosni i Hercegovini [Časopis] // FBIM Transactions / ur. Čekerevac Zoran. - Beograd : MESTE, 1504 2020. - 1 : T. 8. - str. 10-20.

Style - Harvard Anglia:

Baljak, M., 2020. Pregovaranje i zaključivanje sporazuma o priznanju krivice u Bosni i Hercegovini. FBIM Transactions, 15 04, 8(1), pp. 10-20.

Style - ISO 690 Numerical Reference:

Pregovaranje i zaključivanje sporazuma o priznanju krivice u Bosni i Hercegovini. Baljak, Miroslav. [ur.] Zoran Čekerevac. 1, Beograd : MESTE, 1504 2020, FBIM Transactions, T. 8, str. 10-20. 